\title{
O TURISMO E OS ÍCONES URBANOS E ARQUITETÔNICOS
}

\author{
Ricardo Alexandre Paiva
}

\begin{abstract}
R E S U M O : Este artigo analisa teórica e historicamente a relação entre o turismo e os icones urbanos e arquitetônicos, enfatizando o seu papel no panorama contemporâneo. Enfoca ainda a importância destes artefatos (edifícios e grandes projetos e intervençôes urbanas) no contexto da produtividade e competitividade urbanas e, consequentemente, na veiculação da imagem turística dos lugares. Discute-se criticamente como a lógica do consumo reforça a relação entre o turismo, os icones urbanos e arquitetônicos e a imagem turística, que, condicionada pelas práticas sociais (econômicas, políticas e cultural-ideológicas) da globalização, tem direcionado sobremaneira o planejamento, a gestão, as intervençôes urbanas, assim como o processo de espetacularização da arquitetura e valorização da sua carga simbólica.
\end{abstract}

P A L A V R A S - C H A V E : icones urbanos e arquitetônicos; turismo; arquitetura; intervenção urbana; placemarketing; imagem turística.

\section{INTRODUÇÃO}

Este artigo analisa a relação entre o turismo e os ícones urbanos e arquitetônicos, enfatizando o seu papel no panorama contemporâneo. Enfoca ainda a importância destes artefatos (edifícios e grandes projetos e intervençóes urbanas) no contexto da produtividade e competitividade urbana e, consequentemente, na veiculação da imagem turística dos lugares.

As intervençôes urbanas e os edifícios emblemáticos cumprem um papel fundamental na criação de atrativos turísticos. Aliás, o turismo não só estimula a criação de novas configuraçóes urbanas e arquitetônicas, como se vale das existentes, inclusive as concebidas e erguidas dentro de contextos histórico-sociais absolutamente distintos no tempo e no espaço. A motivação da construção destes artefatos não guardava nenhuma relaçáo com o turismo, pois eles tinham sua função relacionada à afirmação do poder político ou religioso, ao poder econômico ou, mais recentemente, à lógica da produção industrial e aos avanços tecnológicos da modernidade.

$\mathrm{Na}$ contemporaneidade, a lógica do consumo reforça a relação entre o turismo, os ícones urbanos e arquitetônicos e a imagem turística, condicionada pelas práticas sociais (econômicas, políticas e cultural-ideológicas) da globalização que têm direcionado sobremaneira o planejamento, a gestáo e as intervençóes urbanas em consonância com o processo de espetacularização da arquitetura e valorização da sua carga simbólica. Sendo assim, o artigo apresenta uma análise crítica da relação entre o turismo e os ícones, discutindo, sobretudo, as suas articulações e contradições com a produção da arquitetura e dos grandes projetos urbanos na atualidade. 


\section{O ÍCONE URBANO E ARQUITETONNICO: BREVES REFLEXÕES CONCEITUAIS}

$\mathrm{Na}$ contemporaneidade, a palavra ícone conserva muito do seu significado original grego (eikón) associado à “imagem”. Sendo assim, ícone, do ponto de vista semântico, significa de modo geral uma representação (imagem, figura, retrato ou ilustração). O conceito de ícone está atrelado historicamente a imagens religiosas produzidas na Idade Média, sobretudo relacionadas às representaçôes pictóricas sacras do evangelho cristão, umas das principais manifestações artísticas bizantinas.

A relação de origem entre o conceito de ícone e a religião confere um caráter sagrado a estes "entes icônicos" (eventos, pessoas e objetos) e suas representaçóes, atribuindo-lhes uma espécie de aura, nos termos discutidos por Walter Benjamin no ensaio $A$ obra de arte na era da sua reprodutibilidade técnica: "Em suma, o que é a aura? É uma figura singular, composta de elementos especiais e temporais: a aparição única de uma coisa distante, por mais perto que ela esteja” (BENJAMIM, 1985, p. 170).

Para Chauí(2002), a qualidade de aura de uma obra de arte tem sua gênese na intricada relação entre a arte e a religiâo, que possuía a finalidade de sacralização e divinizaçáo do mundo, mantendo uma forte afinidade com o sentido de ícone. A aura também se identifica com a absoluta singularidade de um ser - natural ou artístico - e seu caráter único e de simultaneidade da eternidade e fugacidade, inserido na contemporaneidade de seu tempo e carregado da tradição que lhe dá sentido (CHAUÍ, 2002).

Este atributo aurático, no sentido de sagrado, ainda que a atividade artística tenha se tornado autônoma em relação à religiáo, comparece em grande medida nas organizaçóes espaciais qualificadas como ícones urbanos e arquitetônicos, objetos únicos e excepcionais, quase divinos, como os palácios, templos, igrejas e monumentos honoríficos ou funerários.

Entretanto, é importante esclarecer que o conceito de ícone é ambíguo, uma vez que pode se referir à coisa propriamente dita (o ente icônico) ou a sua representação

1 “O signo é uma coisa que representa uma outra coisa: seu objeto. Ele só pode funcionar como signo se carregar esse poder de representar, substituir uma outra coisa diferente dele. Ora, o signo não é o objeto. Ele apenas está no lugar do objeto" (SANTAELLA, 1983, p. 12). Este conceito se baseia na semiótica pierciana.

2 A distinção entre tipo e modelo se encontra bastante sistematizada por Giulio Carlo Argan (2006) no ensaio Sobre a tipologia em arquitetu$r a$, que, baseado no conceito histórico de Quatremère de Quincy, esclarece que o tipo é uma abstração, ao passo que o modelo se identifica com um único exemplo, com conceitos pré-estabelecidos ou bem definidos; o modelo se presta a mimese (imitação), o tipo não. (a imagem), ambas constituindo linguagens nấo-verbais. Aliás, esta distinção entre o objeto e sua representação encontra fundamento teórico no campo disciplinar da semiótica, que define um ícone como um signo ${ }^{1}$ visual que representa o objeto por semelhança ou similaridade, podendo substituir e manter o significado da coisa representada mesmo na sua ausência.

Este argumento teórico permite compreender não somente a importância dos ícones urbanos e arquitetônicos como artefatos materiais essenciais na produção e consumo do espaço turístico, mas também das suas representaçôes, relacionadas às imagens dos lugares turísticos na contemporaneidade.

É importante, ainda, estabelecer os limites entre o ícone como uma representação e a sua reprodução, que o aproxima mais do conceito de "modelo" e/ou "tipo" 2 . A premissa de repetiçáo imbuída na ideia de modelo e/ou tipo se contrapóe ao atributo de originalidade e unicidade intrínseco às características do ícone urbano e arquitetônico. Portanto, um edifício pode ser icônico e, simultaneamente, servir como modelo para um conjunto de edifícios da mesma tipologia ou mesmo se tornar canônico, ao impor regras à produção de outros edifícios no contexto de um movimento arquitetônico mais ou menos homogêneo.

Enfim, de algum modo a definiçáo histórica de ícone em arquitetura pode ser contraditória, pois existe a possibilidade de um edifício exemplar funcionar como 
uma representação matriz para a produção de outros exemplares, repercutindo na sua imitação e tornando os edifícios derivados, assim, ordinários.

Para Sklair (2010), os ícones se referem genericamente a eventos, pessoas e objetos, que são famosos dentro do seu campo em questão e para o público em geral e que possuem sobretudo, e em primazia, um significado simbólico e estético associados. Ainda para o autor, o ícone arquitetônico pode ser conceituado como "os edifícios e espaços que (1) são famosos por aqueles envolvidos diretamente com a arquitetura e/ ou o público em geral e (2) têm um significado estético/simbólico especial "(SKLAIR, 2010 , p. 136, tradução nossa).

$\mathrm{O}$ aspecto estético associado aos ícones se manifesta na sua forma e linguagem arquitetônica ou urbanística. Esta notoriedade e relevância dos ícones urbanos e arquitetônicos se evidenciam na sua materialidade intrínseca, explicitada na maioria das vezes pela sua escala, monumentalidade, proporção, tratamento das superfícies, inserção espacial, distinção formal, relação com o ambiente natural, entre outros aspectos.

Entretanto, esta definição dos ícones arquitetônicos pode ser estendida aos conjuntos e complexos urbanos, onde os próprios edifícios singulares concorrem para qualificar determinadas organizaçôes espaciais construídas como icônicas, como praças, parques, logradouros, esplanadas, etc.

É importante destacar que as configurações espaciais naturais com características notáveis e espetaculares (acidentes geográficos e paisagens naturais), isoladamente ou em conjunto com ambientes construídos, possuem uma forte carga icônica (enquanto objeto e imagem) e são amplamente utilizadas como recursos e atrativos turísticos.

É possível inferir que os ícones urbanos e arquitetônicos possuem uma permanência não só no espaço mas no tempo, passando ao longo da história por transformaçóes no processo de produção, representação e interpretação.

\section{ÍCONES URBANOS E ARQUITETÔNICOS: UMA PERSPECTIVA HISTÓRICA}

Em vários lugares do mundo e em diversos períodos históricos, a transformação da natureza pela cultura produziu inúmeros artefatos construídos pelos homens (cidades, complexos urbanos, infraestruturas, edifícios das mais variadas tipologias, obras de arte, etc), que, pela materialidade e permanência na paisagem, converteram-se em autênticos ícones, seja porque foram criados para tal fim ou porque tal predicado lhe foi concedido ao longo do tempo. É remoto o papel da intervenção urbana e da arquitetura na criação de ícones que sintetizaram, no ambiente construído e em suas representações simbólicas, aspirações culturais e ideológicas das mais diversas (religiosas, políticas, étnicas, econômicas, etc.).

Estas pretensóes sociais (econômicas, políticas e cultural-ideológicas) e os significados históricos agregados aos ícones urbanos e arquitetônicos os aproximam da condiçấo de monumentos, pois se relacionam com a manutenção e a preservação de uma identidade e/ou memória coletiva, religiosa, nacional ou familiar. A condição de monumento (histórico), entendido como "tudo o que for edificado por uma comunidade de indivíduos para rememorar ou fazer que outras geraçóes de pessoas rememorem acontecimentos, sacrifícios, ritos ou crenças" (CHOAY, 2001, p.18), imbuída nos ícones, prolonga a sua existência como autênticos testemunhos históricos, prota- 
3 Pelos cânones da História da Arte, o termo clássico é mais utilizado para Grécia e Roma. gonistas da memória e, como tal, constituem importantes recursos para a reprodução da atividade turística.

Além da sua carga simbólica, atribuída enquanto valor cultural pela sociedade à época de sua construção, a condição de monumento pode ser reforçada por um processo contínuo no espaço e no tempo de ressignificação, transformando-os em ícones.

A princípio, estes ícones urbanos e arquitetônicos não guardavam nenhuma relação com a atividade turística, nem possuíam um alcance em escala global como se verifica na atualidade. Gradativamente, com a emergência da modernidade e a rápida transformação da paisagem, da cidade e da cultura ensejada por esta, muitos destes artefatos históricos passaram a ser objeto de interesse de estudo, preservação e visitação, concomitantemente com o início das viagens organizadas da aristocracia em fins do século XVIII e início do XIX, os "Grand Tours". No século XX, com o turismo de massa, estes ícones históricos foram transformados em atrativos turísticos, aumentado assim o fluxo de visitação, consoante o desenvolvimento dos meios de transporte e comunicação.

Sendo assim, os edifícios icônicos da Antiguidade 3 , como as Pirâmides do Egito, o Parthenon em Atenas e o Coliseu em Roma; as monumentais catedrais medievais e as grandes realizaçóes do Renascimento; as obras persuasivas do Barroco secular (como o Palácio de Versalhes) e religioso (a Praça e a Basílica de São Pedro) - só para citar alguns poucos exemplos - são incorporados no século XIX ao imaginário das viagens e da valorização das paisagens construídas no Ocidente e, posteriormente, no século $\mathrm{XX}$, juntamente com uma série de outros edifícios e complexos urbanos do século XIX (neoclássicos e ecléticos), são capturados como recursos importantíssimos para o desenvolvimento da atividade turística.

A virada do século XIX para o XX testemunha a construção de edifícios que passam a celebrar, predominantemente, os avanços tecnológicos (materiais e técnicas) da construção civil, decorrentes da emergente industrialização. As grandes feiras e exposiçôes internacionais foram importantes eventos mundiais, que ocasionaram muitas viagens e visitaçóes. Some-se a isto a construçáo de espaços e pavilhôes para fins de exposição, na sua maioria efêmeros e temporários, que representavam os avanços da modernidade, presentes tanto nos edifícios em si como nos artefatos que abrigavam (máquinas, invenções, etc).

A Torre Eiffel, erguida no contexto da Exposição Universal de 1889 em Paris, constitui um dos exemplos mais alegóricos da consagração dos progressos da modernidade e, embora tenha sido concebida para ser uma estrutura provisória, acabou se tornando uma construçáo permanente, que pela sua forma, arrojo, verticalidade e inserção urbana se converteu em um dos ícones urbanos e arquitetônicos mais significativos da história, sendo continuamente ressemantizado como atrativo turístico, muito embora não constitua um edifício em si, posto que foi projetada ela mesma como um ícone.

Note-se que, à época de sua realização, a construção da Torre Eiffel enfatizava sobremaneira a lógica da produção industrial, explicitando as possibilidades técnicas do aço na construção, inovando nos processos de pré-fabricação, no cálculo estrutural, no transporte e na montagem e desmontagem, evidenciando as propriedades do ferro (sobretudo em vencer grandes vãos). $\mathrm{O}$ destaque dos aspectos da lógica industrial e funcionalista que a Torre representava, como símbolo da modernidade, se confirma na análise de Argan (1992): 
É uma construção tecnicamente funcional, cuja única finalidade, porém, é dar visualidade e magnitude aos elementos de sua estrutura; sua inegável função representativa (é o ponto alto da exposição, mas torna-se imediatamente o símbolo da Paris moderna, assim como o Coliseu é o símbolo da Roma antiga e a cúpula de São Pedro o da Roma católica) se cumpre na representaçấo de sua funcionalidade técnica (ARGAN, 1992, p. 85).

Historicamente, estes ícones urbanos e arquitetônicos, como a própria torre Eiffel, funcionam como marcos na paisagem urbana, transformando e delineando o skyline das cidades, superando os anteriores, glorificando o futuro e sinalizando, por meio do ambiente construído, transformaçóes socioespaciais importantes (ARGAN, 1992).

Kevin Lynch, em seu trabalho sobre a imagem da cidade, já destacava a importância dos elementos distintos na cidade, que denominava de marcos, pois "a principal característica física dessa classe é a singularidade, algum aspecto que seja único ou memorável no contexto" (LYNCH, 1997, p. 88), além de se prestarem à legibilidade urbana, transformam-se, na maioria das vezes, em atrativos turísticos.

O uso do aço na construçáo civil e a invenção do elevador foram importantes avanços materiais da industrialização, que possibilitaram a verticalização urbana em conformidade com a valorização da terra e da renda fundiária no contexto de urbanização dos principais centros urbanos mundiais. Após o surgimento dos arranha-céus no final do século XIX, em Chicago, estes tipos arquitetônicos disseminaram-se, sobretudo nas cidades americanas, e passaram a ser importantes marcos na paisagem urbana. Os arranha-céus como o Empire State Building, o Rockefeller Center e o Chrysler Building, construídos ainda na primeira metade do século XX, isoladamente ou compondo o skyline de Nova York, converteram-se em atrativos turísticos e representavam o poder econômico corporativo do capitalismo industrial e da potência dos Estados Unidos. No segundo pós-guerra, a construção dos arranhacéus se ampliou não só nas cidades americanas mas também em várias metrópoles em todo o mundo. Atualmente, estes skyscrapers continuam exercendo um papel importante como ícones, contribuindo para a imagem turística dos lugares, embora motivados por outras condicionantes.

O conteúdo programático e social do Movimento Moderno internacional na arquitetura, desde as origens na vanguarda da década de 1920 até a década de 1960, comprometeu-se com a modernização do ambiente construído, inspirado na lógica funcionalista da estética industrial e na busca por processos de produção em massa, redundando, de modo geral, em uma linguagem arquitetônica abstrata, austera e desprovida de ornamentos e apelos simbólicos. A crítica ao Movimento Moderno recaiu sobremaneira na perda da sua capacidade associativa e comunicativa e num certo reducionismo da linguagem, independentemente da tipologia arquitetônica (MONTANER, 2001, p. 12). Moreira (2008) acusa que os edifícios modernos não se prestavam à criação dos atrativos turísticos e de uma arquitetura singular e única (icônica), afirmando que:

[...] a reprodução em massa, com pouca criatividade/qualidade, oriunda do estilo moderno provocou a standardização e a banalização da arquitetura, formada por conjuntos arquitetônicos que imprimem o pavimento-tipo e os mesmos elementos de fachada como oferta imobiliária, fruto do processo de industrialização. (MOREIRA, 2008). 
Não resta dúvida que o ideário moderno focou as suas proposições na solução de programas de necessidades e equipamentos urbanos como escolas, hospitais, habitação e infraestruturas em geral, ou seja, tipologias arquitetônicas que não se identificam com os edifícios icônicos e não constituem necessariamente pontos turísticos, muito embora sejam essenciais para a composição da infraestrutura urbana. Por outro lado, a arquitetura moderna, dependendo da tipologia, deixou um legado de edifícios extremamente significativos que foram convertidos em atrativos turísticos, como é o caso do Museu Solomon R. Guggenheim de Frank Lloyd Wright e do Seagram Building de Mies Van der Rohe, ambos em Nova York, da Sydney Opera House em Sydney, do arquiteto Jørn Utzon, além de muitos outros edifícios projetados por grandes mestres como Le Corbusier, Walter Gropius e tantos outros de alcance mais regional.

O exemplo de Brasília é expressivo para desconstruir a ideia generalizada de que o urbanismo e a arquitetura modernos não possuem um caráter simbólico associado. $\mathrm{O}$ eixo monumental de Brasília constitui um espaço altamente qualificado que valoriza alguns edifícios singulares como focos perspectivos, como a Catedral, a Praça dos Três Poderes e os Palácios da Alvorada e da Justiça. Independentes ou agrupados, funcionam como importantes ícones urbanos e arquitetônicos, que pela sua forma e disposição urbanas remetem ao ideário modernizante e desenvolvimentista impregnados no discurso econômico, político e ideológico do Estado.

Os ícones urbanos e arquitetônicos modernistas representavam em grande medida o capital industrial, o Estado Interventor e desenvolvimentista e a burguesia moderna, mas não havia uma intenção propriamente consciente de produzir atrativos turísticos nos moldes da produção da arquitetura e intervençáo urbana contemporâneas.

Ainda numa perspectiva histórica, outro aspecto que cabe ressaltar é a evolução dos ícones (enquanto imagem) em relação às limitaçôes de representação gráfica destes objetos. A literatura, seguramente, cumpriu um papel fundamental na descriçáo destes artefatos urbanos e arquitetônicos ao longo da história, divulgando a sua excepcionalidade e a sua mensagem simbólica, mas devendo muito em termos de representação, por não constituir a linguagem mais apropriada para representar ou funcionar como um signo gráfico. O surgimento das primeiras representaçóes dos ícones urbanos e arquitetônicos foi possível por intermédio da pintura (mural ou quadro), sobretudo a partir do Renascimento, que promoveu uma sistematizaçáo histórica dos monumentos da antiguidade e fez circular, principalmente nos meios eruditos, a importância não somente dos edifícios clássicos antigos mas dos edifícios modernos que passaram a projetar e construir. Cabe destacar também o papel da perspectiva científica, a partir do século XIV, como importante meio de concepçáo e representação do espaço para a sociedade moderna que emergia no contexto do capitalismo mercantil, além da imprensa gráfica, que de alguma forma colaboraram como meios de representaçáo dos ícones urbanos e arquitetônicos.

Com o advento da fotografia na segunda metade do século XIX e a democratização do uso da imagem, uma vez que as imagens pictóricas (lugares e retratos) estavam restritas a um público seleto, a representação dos entes icônicos (eventos, pessoas e objetos) facilitou sobremaneira a circulação de informaçôes, criando assim uma relação de oferta e demanda por conhecimento real e imaginário destes artefatos, conferindolhes importância ainda maior e suscitando uma espécie de culto às suas imagens.

Os cartôes postais dos lugares foram um meio de representaçáo importante de divulgação dos ícones urbanos e arquitetônicos, auxiliando na mitificação de muitas 
paisagens naturais e culturais. A princípio eram impressos com gravuras e, a partir de 1891, com imagens fotográficas. A sua circulação despertava o interesse das pessoas em viajar, aumentando a demanda e estimulando, promovendo e projetando as imagens dos lugares enquanto destinos turísticos.

Podemos dizer que o cartáo-postal vem a ser elemento de referência em todas as etapas desse ciclo (de viagens): antes do evento como fator de estímulo que desperta o desejo ou que insere o lugar a ser visitado no repertório do consumidor do produto turístico; durante a viagem como produto de consumo, de afirmaçấo social, e de apropriaçáo e registro do lugar e da experiência gerada por ele; no retorno, o cartáo-postal é elemento de prolongamento da experiência turística, da confirmação da realizaçáo da viagem, de afirmação social e de status perante os grupos de relacionamento, de compartilhamento da experiência e de organização da memória em relação à série de eventos ocorridos (FRANCO, 2006, p. 42, grifo do autor).

A disseminação dos ícones arquitetônicos como imagens que antecedem e prolongam as experiências que envolvem as viagens e o turismo são representadas pela reprodução em miniatura de lugares e monumentos, compondo uma das categorias dos variados tipos de souvenires (maquetes, chaveiros, entre outros) que remetem ao ícone, e que são itens fundamentais de compras nas viagens, pelos valores de signo que lhes são inerentes (Figura 1).

Figura 1: Miniaturas de ícones urbanos e arquitetônicos

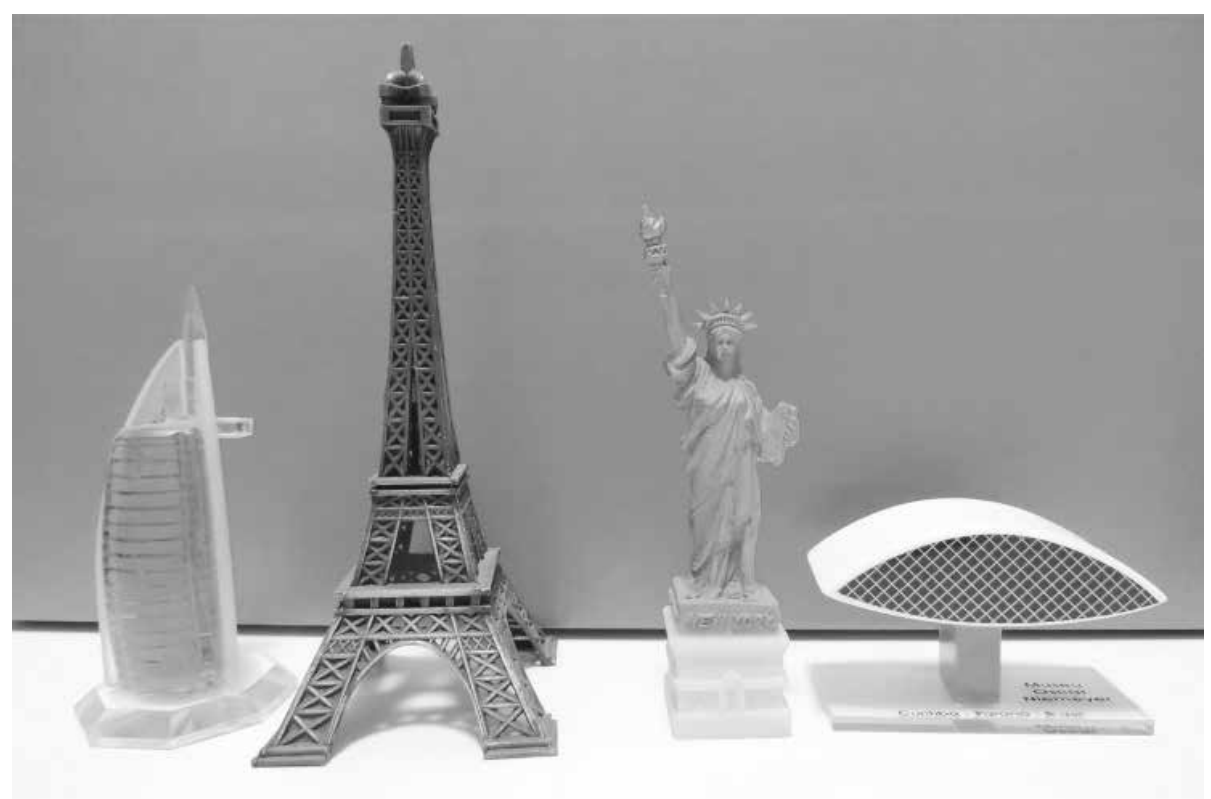

Fonte: Acervo do autor.

A representação, interpretação e circulação dos ícones na atualidade estão condicionadas pelos avanços tecnológicos na produção e divulgação de imagens, associadas à lógica do consumo dos lugares e imagens que caracterizam o turismo contemporâneo. 


\section{TURISMO E GLOBALIZAÇÃO}

Sklair (2010) argumenta que a produção e representação dos ícones arquitetônicos (e urbanos) na era pré-globalizaçáo eram dirigidos por quem controlava o Estado e a religiāo e que, na atualidade, na "era do capitalismo global", a força dominante que dirige a produção dos ícones é a "classe capitalista transnacional".

A emergência da classe capitalista transnacional é um sintoma do processo de globalização (SKLAIR, 2010), que pode ser sumariamente compreendido como um processo em que as práticas sociais (econômicas, políticas e cultural-ideológicas) transbordam os limites e fronteiras do Estado e redimensionam e diluem as barreiras espaciais e temporais entre o global e o local, "graças ao desenvolvimento das comunicaçôes contemporâneas e às novas tecnologias computadorizadas que potencializam a reprodução do modo de produção capitalista" (PAIVA, 2011, p. 20).

Esta classe capitalista transnacional ${ }^{4}$ (SKLAIR, 2006) se insere nas práticas sociais

4 "Estas são pessoas de muitas partes do mundo que operam transnacionalmente como uma parte normal de sua vida profissional, mas que muitas vezes têm mais de um lugar que podem chamar de lar." (SKLAIR, 2006, p.

24, tradução nossa). (econômica, política e cultural-ideológica) transnacionais e coexiste com as práticas sociais locais. Assim, é possível admitir que a produção dos ícones urbanos e arquitetônicos se insiram nos fluxos globais, pois "se, em outros momentos, eles possuíam um significado e uma aparência condizentes com a sociedade local, eles agora pertencem à sociedade global' (HAZAN, 2003).

Para fundamentar estes pressupostos, é importante analisar as dimensóes econômica, política e cultural-ideológica da globalização, articulando-as às práticas sociais do turismo.

A dimensão econômica se caracteriza por práticas sociais de produção, distribuição e consumo, em que há a precedência da lógica do consumo em detrimento da lógica da produção fordista, superada, por seu turno, por uma maior flexibilidade e mobilidade do setor industrial, caracterizando a "produção flexível". Neste sentido, emerge um processo de descentralização e internacionalização do capital, sobretudo financeiro, que reforça a hegemonia do terciário avançado, sendo a atividade turística protagonista. Some-se a isto a criação de um mercado global em um cenário de primazia de práticas de consumo cada vez mais complexas relacionadas à celebraçáo da diferença, e o consumo de bens intangíveis em contrapartida ao consumo de bens coletivos e de massa e de bens duráveis característicos da lógica da produçáo. $\mathrm{O}$ turismo se enquadra como importante atividade econômica na lógica do consumo, no conjunto de transformaçôes gerais ocorridas nas práticas econômicas contemporâneas supracitadas com o aumento e especialização do comércio e serviços no setor terciário, tornando-se uma nova "indústria motriz" (VARGAS, 1996), muito embora seja uma atividade suscitada pelo ócio e pelo lazer e não pelo trabalho. Articula a produção e consumo de bens, mercadorias, serviços e lugares e caracteriza-se por ser um turismo flexível, devido à "flexibilidade e a segmentação das demandas e das ofertas turísticas, a busca de uma série de sensações que envolvem o consumo de bens imateriais, experiências intangíveis e serviços diferenciados" (PAIVA, 2012, p. 1016).

A dimensão política se identifica com a superação do Estado de Bem Estar Social (Welfare State) pelo Neoliberalismo, em que prevalece o Estado empreendedor e regulador em detrimento do provedor e interventor. Neste processo, predominam a privatização de bens e necessidades coletivas, o desmantelamento das relaçóes de poder identificadas com os interesses de classe e a emergência de relaçóes de poder mais complexas e transnacionais. $\mathrm{O}$ ponto de interseção da relaçáo entre o turismo 
e as práticas políticas correspondem à incidência das novas atribuiçôes do Estado no processo de acumulação, marcado principalmente pelo planejamento estratégico. Esta nova forma de planejar e gerir a cidade incrementa políticas públicas que favorecem a atuação do mercado, estimula a produtividade e competitividade urbanas, valorizando a imagem turística dos lugares e sua promoção através das estratégias de placemarketing. Há o favorecimento do poder político das elites globais e locais e assimetrias de poder econômico e político entre turistas e residentes.

A dimensão cultural-ideológica se refere às práticas sociais que possuem um alcance simbólico. Na contemporaneidade, é possível perceber a importância de valores culturais fragmentados e plurais em consonância com as práticas diferenciadas e individuais de consumo, sinalizando uma tendência crescente de mercantilização da cultura no contexto da sociedade do espetáculo. O turismo é uma prática social por excelência de emissão, transmissão e recepção de mensagens dos valores culturais e ideológicos, "permitindo a troca constante de conteúdos simbólicos da cultura, da arte, da religiáo, do folclore, dos modos de vida, da culinária, da indumentária, da moda, etc." (PAIVA, 2012, p. 1020). O espaço, contudo, se torna um dos principais meios de expressão dessas práticas cultural-ideológicas, sendo as características particulares do ambiente construído e natural insumos importantes para as práticas de consumo de experiências e de bens intangíveis suscitadas pelo "turismo flexível".

É importante destacar que estes aspectos de ordem cultural-ideológica sintetizam os aspectos simbólicos das demais práticas sociais (econômicas e políticas). Jameson (1996) confirma esta relação ao associar a lógica cultural do capitalismo tardio ao pós-modernismo.

A concepção dos ícones urbanos e arquitetônicos no atual processo de globalização constitui uma das estratégias centrais empregadas para a construção e reforço da imagem turística dos lugares, assim como serve para atrair investimentos públicos e privados para as cidades e regióes. Trata-se de um processo crescente de mercantilização da cultura, transformada em insumo para obtenção de vantagens econômicas.

A fim de qualificar essa imagem para o consumo, pois o ícone sintetiza e se confunde com a própria imagem urbana ${ }^{5}$, o turismo, inserido nas políticas públicas das diversas instâncias do poder, se vale das estratégias do placemarketing, que preconiza, entre outros aspectos, a divulgação dos lugares em escala mundial, contribuindo para tal objetivo as redes de informação e comunicação contemporâneas.

Segundo Sánchez (2003, p. 40), "a construção de imagens e do marketing de cidade é tratada como parte dos processos políticos e culturais dinâmicos que devem ser apreendidos na compreensão das formas de produção do espaço contemporâneo". A promoção da imagem da cidade na contemporaneidade, nas escalas global e local, situa-se entre as principais práticas preconizadas pelo receituário proposto pelo planejamento estratégico.

Vainer (2002), ao criticar o planejamento estratégico, identifica as diferenças com relação ao planejamento tradicional ao afirmar que a preocupação agora, contrária aos temas como crescimento desordenado, reprodução da força de trabalho, equipamentos de consumo coletivo, movimentos sociais urbanos, direciona-se para a produtividade e a competitividade urbanas, sendo o turismo uma das principais atividades nesse processo.
5 Neste sentido, imagem urbana "[...] corresponde à informação solidamente relacionada com um significado que se constrói numa síntese de contornos claros que a faz única e intransferível. [...] É um código urbano e impõe uma leitura e fruição que estão claramente inscritos na cidade como espaço construído" (FERRARA, 2000, p. 118). 


\section{OS ÍCONES URBANOS E ARQUITETONICOS CONTEMPORÂNEOS}

A concepçáo dos ícones urbanos e arquitetônicos contemporâneos relaciona-se, em muitos aspectos, à valorização dos lugares como cenários do consumo, e por isso mesmo funcionam como catalisadores do desenvolvimento urbano, profundamente intricados à lógica do turismo.

A despeito da diversidade das premissas da produção da arquitetura e da intervenção urbana contemporâneas, muitas de suas tendências e posturas se alinham simbolicamente às práticas cultural-ideológicas da sociedade do consumo, pois:

Assim como a arquitetura e o urbanismo modernos refletiam a lógica capitalista da produção, buscando associaçóes estéticas, técnicas e funcionais com a racionalidade industrial, ao que tudo indica, a arquitetura contemporânea se sustenta na lógica do consumo, reproduzindo e criando uma diversidade e variedade estética, técnica e funcional condizente com o processo contemporâneo de acumulação. (PAIVA, 2011, p. 248).

Harvey (2005) argumenta que os artefatos e as práticas culturais, assim como as características ambientais particulares dos lugares, são o melhor campo para se obter a "renda monopolista".

Toda a renda se baseia no poder monopolista dos proprietários privados de determinadas porçóes do planeta. A renda monopolista surge porque os atores sociais podem aumentar seu fluxo de renda por muito tempo, em virtude do controle exclusivo sobre algum item, direta ou indiretamente, comercializável, que é, em alguns aspectos, crucial, único e irreplicável. (HARVEY, 2005, p. 28).

Neste sentido, a "renda monopolista" dos ícones urbanos e arquitetônicos na contemporaneidade se direciona para a criação de uma forma urbana e arquitetônica singular e notável.

Esta forma distinta se identifica com a acepção de "capital simbólico" proposta por Bordieu e reinterpretada por Harvey como sendo "capital simbólico coletivo", e tem relação direta com a atividade turística, na medida em que o turismo se ampara nas singularidades dos recursos turísticos a fim de transformá-los em atrativos.

O conceito de "renda da forma" (ARANTES, 2012), que descende do conceito de "renda monopolista" de Harvey (2005), constitui uma reflexão recente importante para a compreensão das tendências da arquitetura contemporânea identificadas com a produção dos ícones urbanos e arquitetônicos, já que a "renda da forma" confere prioridade ao ineditismo da forma única e espetacular e valoriza a arquitetura

6 Trata-se, segundo Arantes (2012), de uma arquitetura de exceção, seja porque constituem uma porcentagem muito pequena da produção arquitetônica global, seja porque são "fatos primários" da cidade. como imagem ${ }^{6}$.

Por isso, essa arquitetura obtém mais dividendos na circulação do que com sua produção; ou melhor, sua produção é comandada pelos ganhos advindos da sua divulgação midiática e da capacidade de atrair riquezas (por meio de investidores, turistas, capacitação de fundos públicos, etc.). (ARANTES, 2012, p. 18). 
Malgrado as diferenças conceituais, éticas e estéticas da diversidade e heterogeneidade de "posturas arquitetônicas" na atualidade, prevalece na arquitetura contemporânea um gosto formalista, superestimando a sua capacidade comunicativa de expressar conteúdos simbólicos, que vem reduzindo a arquitetura à pura visualidade, à imagem que pode ser veiculada e convertida em espetáculo para alimentar o consumo dos lugares.

A diferença é que, agora, essa força espetacular da arquitetura não é mais requisito único de regimes absolutistas, autocráticos ou fascistas, mas de grandes estratégias de negócio associado ao turismo, a eventos culturais e esportivos, ao marketing urbano e à promoçáo das identidades empresariais. (ARANTES, 2012, p. 55).

A produção dos ícones se alinha ao universo das práticas de consumo e da afirmação do capital financeiro e corporativo, da indústria do entretenimento, das marcas, das estratégias de marketing e dos aspectos intangíveis que envolvem os bens materiais, as experiências e as sensaçôes imateriais.

A lógica do consumo transcende a fabricação dos objetos, posto que o "capital simbólico coletivo" a eles associado é o que verdadeiramente cria uma valorização financeira e permite a obtenção do lucro, ou seja, a reprodução do capital com uma base não produtiva (cultura, lazer, megaeventos e turismo), gerando uma economia simbólica, em que o capital virtualiza-se. Sendo assim, a intervenção urbana, a arquitetura e acultura em geral adquirem a condição de mercadoria altamente valorizada.

Em conformidade com a visão de Baudrillard (2008), o consumo de objetos determinados pela necessidade tem uma ligaçáo com o valor de uso, ao passo que o consumo associado à lógica do desejo tem ligação com o valor de troca, mas também com o valor de signo, ou seja, pelo seu valor enquanto expressão da distinção social e individual, expresso e reproduzido nas imagens e nas marcas atreladas aos objetos, justificando a proliferação dos ícones urbanos e arquitetônicos no contexto da competitividade e produtividade dos lugares turísticos.

De modo geral, a arquitetura contemporânea valoriza excessivamente a superficialidade da forma. Tal premissa remonta as críticas de Venturi, Brown e Izenour (2003) à arquitetura moderna na década de 1960, ao advogar a ideia do "duck" e do "decorated shed" (que pode ser traduzido como "pato" e "galpão decorado", respectivamente), que consiste na valorização da forma em detrimento da função. O edifício se converte em imagem, substitui-se a espacialidade pelo simbolismo, pois o "[...] elemento que caracteriza cada edifício é o vestuário, a ornamentação, o tratamento epidérmico, a estrutura e o interior constituem um mero fato construtivo, de engenharia, funcional.” (MONTANER, 2001, p.162). Estes recursos superficiais e cosméticos empregados na fachada são utilizados para qualificá-los como "edifícios propaganda". Esta arquitetura "à flor da pele" se enquadra nas características dos ícones propostos por Mateo (2009), ao afirmar que eles são pura pele, uma epiderme espetacular; sendo assim, os ícones arquitetônicos não possuem espaço, não têm interior, se existe um espaço interior, ele não interessa.

Para reforçar imagens sintéticas e de fácil reconhecimento das marcas (cidades, lugares, empresas, entre outros), às quais estáo associados os edifícios contemporâneos, os ícones são arquitetados como se fossem obras de arte ou objetos do design, procurando sustentar a aura artística destes artefatos. Isto ocorre consoante os próprios métodos
7 Baseiam-se "[...] na consideração que certos arquitetos oferecem opções de tipo de espaços, materiais, linguagem, tecnologias e relações com a cidade. Essas opções mantêm uma certa coerência e permitem delimitar certas posturas determinantes" (MONTANER, 2001, p. 178). 
de projeto dos arquitetos-artistas, pois "se renuncia, por princípio, à produção em série e à industrialização radical; cada obra, em compensação, será singular e manterá uma relação única e instrumental com: o contexto, o usuário ou com as arquiteturas preexistentes"(MONTANER, 2001, p. 217).

A aproximação entre a arquitetura e a arte contemporâneas se revela também no interesse em despertar a surpresa, a interação com o objeto proposto, apostando na experiência sensorial e na percepção e interpretação individuais do fruidor.

Neste contexto de produção de uma arquitetura da diferença ou de exceção, quase como objeto de arte ou do design, recorre-se comumente às formas escultóricas, sejam as puras e minimalistas, formas sintéticas e de fácil reconhecimento, sejam as formas complexas, às vezes com referências figurativas ou desconstruídas, estas últimas com o intuito de transgredir a geometria euclidiana.

No caso em que há associaçôes figurativas, os ícones potencializam seu alcance e visibilidade, pois se referem a figuras e objetos do conhecimento do público leigo. Mesmo nas situaçóes em que comparece uma maior abstração formal ou excessiva extravagância, acaba se estabelecendo uma associação com figuras, sobretudo pelos "não iniciados".

O consumo associado aos ícones urbanos e arquitetônicos se insere nas práticas de lazer e do turismo, pois em ambos percebe-se uma forma de distinção social monopolizada pela criaçáo e consumo de bens diferenciados. Em certa medida, as intervençóes urbanas e as arquiteturas icônicas se expressam como espaços de uso público, mas na maioria dos casos o uso e a visitação por turistas destes espaços são restritivos, pois são espaços coletivos de acesso público, mas com controle privado. Na verdade, trata-se da construção de espaços idealizados e homogêneos que, como os parques temáticos, buscam minimizar as assimetrias sociais tão recorrentes nos espaços não-simulados (ZUKIN, 2003), restringindo-se aos que possuem os meios materiais para consumir os bens tangíveis e intangíveis vinculados aos ícones urbanos e arquitetônicos.

A condição de um edifício ou intervenção urbana se tornar icônica antecede a sua materialização enquanto obra. O projeto já anuncia a sua condição de ícone, pois é formatado como um produto, uma mercadoria. O projeto já é uma representação, um esboço da imagem que o ícone sintetiza, concorrendo para a sua mitificação ao alcançar tal status, antes mesmo de ser construído.

Concorrem para isso as novas tecnologias digitais e da informação no campo não exclusivo da arquitetura e da engenharia, mas no processo produtivo em geral. Percebe-se que os meios de representação contemporâneos e as tecnologias digitais estáo a serviço da criaçáo de uma hiper-realidade, simulando o espaço real com uma fidelidade e resolução inimagináveis. Trata-se de uma "hiper-representação" que, por vezes, oculta aspectos da realidade e do contexto urbano do edifício, dissimulando inclusive atributos específicos da arquitetura e da intervenção urbana.

As novas tecnologias digitais e informacionais repercutem na mitificação do ícone ao proporcionar a veiculaçáo das suas representaçôes de forma instantânea através dos meios de comunicação, sobretudo a internet, e ao possibilitar a edição das imagens, valorizando ângulos diferenciados e inusitados, corrigindo possíveis defeitos, excluindo do contexto da fotografia elementos da paisagem desfavoráveis para a sua difusão. Estas correçóes possibilitadas pela tecnologia digital geram um descompasso entre o ente icônico (objeto) e a sua representação (imagem), provocando, por vezes, uma certa frustraçáo por parte dos turistas e visitantes, muito embora a experiência do 
registro da imagem e o seu compartilhamento, facilitados pelos smartphones, câmeras digitais e redes sociais, tendam a ter primazia sobre a experiência concreta da percepção e interpretação do espaço construído. Estas imagens digitais, agora banalizadas pela facilidade de sua aquisição, substituem o papel representado pelos cartóes-postais na modernidade.

Os edifícios icônicos se identificam com algumas tipologias arquitetônicas específicas, sobretudo com os centros culturais e os museus. Ao contrário da postura dos arquitetos modernos, que os concebiam como ambientes neutros e como pano de fundo para as obras de arte, os edifícios para fins culturais na atualidade, sobretudo os museus, são concebidos eles mesmos como objetos de arte, shoppings centers da cultura, desejo de realizaçáo dos starchitects ${ }^{8}$.

O programa de necessidades dos edifícios culturais também se diversifica e ratifica a sua relação com o consumo, visíveis nas lojinhas de souvenires, nos cafés, na animaçáo cultural promovida pela gestâo dos equipamentos culturais.

No âmbito das práticas arquitetônicas e da construção contemporâneas, a fração corporativa da "classe capitalista transnacional" corresponde ao grupo que controla as principais empresas de arquitetura do mundo e suas filiais locais, na sua maioria lideradas pelos celebrados starchitects, que atuam em escala global.

A contratação de arquitetos famosos, que podem ser considerados também "entes icônicos", agrega valor aos ícones urbanos e arquitetônicos, pois o seu reconhecimento profissional ou sua fama ajudam a mitificar esses ícones desde a sua criação. Os prêmios e concursos internacionais de arquitetura; a articulação dos arquitetos com as marcas, campanhas publicitárias e debates culturais; e a publicação em revistas impressas e digitais de seus projetos emblemáticos sustentam a criaçáo de ícones urbanos e arquitetônicos como uma prática recorrente da arquitetura contemporânea, com impactos incontestáveis na reprodução da atividade turística.

Os starchitects possuem o desafio constante de se reinventarem, para que suas obras não tendam à repetição ou ao esgotamento de soluçóes originais já adotadas e, desse modo, não acompanhem a contento as demandas do mercado e as transformaçóes impostas pela moda e pelos avanços tecnológicos. Sendo assim, o compromisso dos arquitetos parece se voltar sobremaneira para o efêmero e para o apelo suscitado pela economia simbólica.

Os arquitetos da era financeira, ao contrário dos modernos, não procuram soluçóes universalistas, para serem reproduzidas em grande escala - o que reduziria o potencial de renda monopolista da mercadoria. O objetivo é a produção da exclusividade, da obra úni$\mathrm{ca}$, associada às grifes dos seus projetistas e de seus patronos. E a corrida pelo ineditismo é item contratual, pois os clientes solicitam dos arquitetos obras exclusivas em todos os seus detalhes - soluções de fachada, revestimentos e estruturas não podem ser repetidas. (ARANTES, 2012, p. 57-58).

O Centro Georges Pompidou (1977), em Paris, foi um dos primeiros edifícios contemporâneos a se afirmar como ícone urbano e arquitetônico, pelo papel que cumpriu na reabilitação de um distrito urbano da cidade e na propagaçáo em escala mundial da capacidade de Paris de afirmar a sua contemporaneidade cultural e econômica no mundo globalizado.

Várias cidades do mundo apostaram no poder destes ícones urbanos e arquitetô-
8 Conforme Arantes (2000, p. 244):"A crítica do funcionalismo, o elogio a torto e a direito do ornamento, a total liberdade de escolha dos estilos ou soluções construtivas, tornam o museu um lugar mais propício a um exercício projetual sem compromissos, onde 0 artista pode mais livremente dar asas à imaginação [...]. Portanto hoje todos os arquitetos querem assinar o seu museu". 
nicos, como foi o caso de Bilbao, com a construçáo do Museu Guggenhein. "O museu se converteu imediatamente em sinônimo de toda uma cidade e um símbolo de regeneração de uma zona problemática da Espanha" (OCKMAN, 2006, p. 261, tradução nossa). O chamado "efeito Bilbao" se transformou no exemplo mais emblemático da capacidade de impulsionar o desenvolvimento turístico a partir da construçáo de um ícone, uma vez que a cidade de Bilbao capturou subitamente a atenção mundial como sendo "a surpresa arquitetônica mais glamorosa deste fim de século" (OCKMAN, 2006, p. 261, tradução nossa), inserindo-se, assim, nos roteiros turísticos da Europa. A estratégia utilizada em Bilbao, que teve seu protagonismo econômico ligado anteriormente à atividade industrial, condição esta que foi subtraída diante da economia pós-industrial, demonstra o poder do turismo enquanto propulsor do desenvolvimento econômico. Jencks (2005) cunha o termo "iconic bulding" para caracterizar o cenário contemporâneo da arquitetura de grife, que tem como exemplo emblemático o caso de Bilbao.

O concurso e a construçáo do novo complexo do World Trade Center em Nova York, após o atentado de 11 de setembro de 2001 que destruiu as Torres Gêmeas (importante signo da cultura arquitetônica americana e internacional), revelam que até mesmo as tragédias (ou a sua superação) funcionam como insumo para a atividade turística e a reinvenção dos ícones urbanos e arquitetônicos na atualidade. O novo complexo, que inclui a construção de novos arranha-céus e o memorial e o museu dedicados à lembrança do evento e das vítimas, elucida o poder da complexa relação entre o apelo simbólico e estético dos ícones urbanos e arquitetônicos e a atividade turística.

Outro exemplo digno de ser mencionado são as mutações urbanas e arquitetônicas em Dubai, que se transformou em um grande canteiro de experiências inéditas suscitadas pelas iniciativas pública e privada no campo do placemarketing e do desenvolvimento do turismo, articulando mercado imobiliário, rede hoteleira e novas relaçóes entre os ambientes natural e construído.

No Brasil, o exemplo mais conhecido da promoção da imagem turística dos lugares, através da construção de ícones urbanos e arquitetônicos, foi em Niterói, com a construçáo do Museu de Arte Contemporânea, e em Curitiba, com o Museu Oscar Niemeyer, ambos projetados pelo arquiteto Oscar Niemeyer, confirmando a importância da autoria para a mitificação do ícone. No Rio de Janeiro, vale ressaltar o projeto da Cidade da Música, do arquiteto Christian de Portzamparc, e o Museu do Amanhã do arquiteto Santiago Calatrava, que ratifica a internacionalização da arquitetura de grife.

Como o objetivo do artigo não é discorrer sobre os diversos exemplos e estudos de caso concebidos e construídos em diversos contextos e escalas, pretende-se reforçar outras tipologias arquitetônicas e urbanísticas que são campo fértil para a materialização dos ícones.

No caso das intervençôes urbanas, destacam-se os processos de reabilitação de áreas degradadas, como as frentes marítimas ou fluviais, complexos industriais e portuários, edifícios de interesse patrimonial, áreas históricas como centros e bairros antigos, que testemunham um processo crescente de gentrificação e turistificação, suscitando diversos conflitos entre o público e o privado.

As infraestruturas urbanas e de transporte (pontes estaiadas, passarelas, terminais de várias modalidades) também têm sido influenciadas pela renda da forma: "As infraestruturas de circulação, sobretudo as associadas ao fluxo de turistas, passaram a ser 
desenhadas como requisitos de ineditismo e exuberância formal similares aos edifícios culturais e esportivos que atraem os visitantes" (ARANTES, 2012, p. 313).

Alguns hotéis, lojas de marcas internacionais e shoppings também foram projetados com apelos formais típicos dos ícones, atraindo uma quantidade significativa de turistas, misturando a experiência de consumo de mercadorias ao consumo dos lugares.

Os programas associados aos megaeventos esportivos (Copa do Mundo de Futebol, Olimpíadas) têm sido também um campo por excelência de produção de ícones urbanos e arquitetônicos, transformando a arquitetura em si mesma um espetáculo.

Vale ressaltar ainda os espaços simulados, como os parques e cidades temáticas, que consolidaram imagens turísticas extremamente marcantes e foram entronizadas como ícones do turismo e do entretenimento pelo imaginário coletivo, produzindo uma arquitetura "fake" com fortes recursos e efeitos simbólicos.

\section{À GUISA DE CONCLUSÃO: POR UMA NOVA ICONOCLASTIA?}

A análise apresentada buscou, através de referências históricas e teóricas, ressaltar o processo de produção, consumo e apropriação do espaço pelo e para a atividade turística, ressaltando as especificidades e contradiçóes contidas na relação entre o turismo e os ícones urbanos e arquitetônicos, sobretudo na atualidade.

Verifica-se que os ícones se referem imensamente à imagem que, análoga às representaçóes e marcas veiculadas nos anúncios de propaganda, estimula o consumo e a venda dos lugares e, como tal, serve para persuadir as pessoas a comprarem. Sendo assim, a experiência do turismo, baseada no lazer e no consumo, torna-se uma prática alienada e de distinção social, repercutindo sobremaneira no processo de acumulação do capitalismo contemporâneo.

O papel histórico de edifícios emblemáticos para o desenvolvimento da atividade turística não é uma novidade, o que é recente é a sua precedência como meio para obtenção da renda monopolista na arquitetura e na intervenção urbana como parte das práticas sociais (econômicas, políticas e cultural-ideológicas) da globalização, marcada pela "desavergonhada mercantilização de tudo" (HARVEY, 2005, p. 39), que escandaliza as desigualdades socioespaciais e fragiliza os lugares.

A atratividade turística está fortemente arrolada às transformaçôes espaciais, não somente representada pela provisão de infraestruturas, mas também pelas intervenções urbanas, pela valorização do patrimônio histórico e cultural e pela recorrência à iconicidade da arquitetura. Sendo assim, é preciso atentar como se vem efetuando essas transformaçóes, guiadas por interesses de grupos privados específicos, das organizaçôes transnacionais e do próprio Estado na manutenção das suas hegemonias econômicas e políticas e cujas açôes devem ser revistas e analisadas, ao se discutirem as formas urbanas resultantes e os impactos no processo de fragmentação e segregação socioespacial.

Não seria, portanto, tempo de anunciar uma nova iconoclastia, um movimento contra a idolatria aos ícones urbanos e arquitetônicos, denunciando a veneraçáo da produção de uma arquitetura superficial, espetacular e efêmera, combatendo a adora- 
Ricardo Alexandre Paiva é arquiteto e urbanista pela Universidade Federal do Ceará (UFC); mestre e doutor em Arquitetura e Urbanismo pela Universidade de São Paulo (USP); professor adjunto do Departamento de Arquitetura e Urbanismo da UFC, Brasil. E-mail: paiva ricardo@yahoo.com.br.

Artigo recebido em março de 2014 e aprovado para publicação em maio de 2014. ção e o culto às práticas de turismo alienadas e predatórias suscitadas pela veiculação das imagens turísticas e dos ícones? Provavelmente não se teria êxito, cabe à arquitetura e ao urbanismo, como objeto do conhecimento e de intervençáo socioespacial, colocar-se a serviço da valorização dos lugares em sentido amplo.

É importante reivindicar, assim, o papel do planejamento urbano, do urbanismo e da arquitetura como instrumentos de gestão, intervençáo espacial e implantação de serviços urbanos básicos, infraestrutura adequada, equipamentos culturais, entre outros, no sentido de criar as bases para intervençóes com fins turísticos. A concatenação de intervençóes voltadas para a população e para os turistas é a base para garantir uma cidade mais democrática e atraente para além da sua imagem.

\section{REFERÊNCIAS BIBLIOGRÁFICAS}

ARANTES, O. B. F. O lugar da Arquitetura depois dos modernos. 3. ed. São Paulo: EDUSP, 2000 .

ARANTES, P. F. Arquitetura na era digital-financeira: desenho, canteiro e renda da forma. São Paulo: Editora 34, 2012.

ARGAN, G. C. Arte Moderna. São Paulo: Cia das Letras, 1992.

Sobre a tipologia em Arquitetura. In: NESBITT, K. (Org.). Uma nova agenda para a arquitetura. Sáo Paulo: Cosac Naify, 2006. p. 267-273.

BAUDRILLARD, J. A sociedade do consumo. Lisboa: Ediçôes 70, 2008.

BENJAMIN, W. A obra de arte na era de sua reprodutibilidade técnica. In: Magia

e Técnica, Arte e Politica. São Paulo: Brasiliense, 1985. p. 165-196. (Obras Escolhidas, v. 1).

CHAUÍ, M. S. Convite à Filosofia. São Paulo: Ática, 2002.

CHOAY, F. A alegoria do patrimônio. São Paulo: Ed. Unesp; Estação Liberdade, 2001.

FRANCO, P. S. Cartóes-postais: fragmentos de lugares, pessoas e percepçóes. Métis: história \& cultura, Caxias do Sul, v. 5, n. 9, p. 25-62, jan./jun. 2006.

FERRARA, L. D. Os significados urbanos. São Paulo: EDUSP; FAPESP, 2000.

HARVEY, D. A arte como renda: globalização e transformação da cultura em commodities. Desígnio: Revista de História da Arquitetura e do Urbanismo, São Paulo: Annablume, n. 4, p. 27-40, 2005.

HAZAN, V. M. O papel dos ícones da contemporaneidade na revitalização dos grandes centros urbanos. Arquitextos, São Paulo, v.4, n. 041.02, out. 2003. Disponível em: <http://www.vitruvius.com.br/revistas/read/arquitextos/04.041/645>. Acesso em: 04 jan. 2014.

JAMESON, F. Pós-Modernismo: a lógica cultural do capitalismo tardio. São Paulo: Ática, 1996. JENCKS, C. The iconic building: the power of enigma. London: Francis Lincoln, 2005.

LYNCH, K. A imagem da cidade. São Paulo: Martins Fontes, 1997.

MATEO, J. L. (Org.). Iconoclastia: news from a post-iconic world. Barcelona: Ed. ETH - Actar, 2009. (Architectural Papers, v. 4).

MONTANER, J. M. Depois do movimento moderno: arquitetura da segunda metade do século XX. Barcelona: Gustavo Gili, 2001.

MOREIRA, A. Turismo e arquitetura: A produção do atrativo via singularidade / notoriedade do lugar. Arquitextos, São Paulo, v. 8, n. 093.05, fev. 2008. Disponível em:<http://www.vitruvius.com.br/revistas/read/arquitextos/08.093/169>. Acesso em: 17 jan. 2014.

OCKMAN, J., La nueva política del espetaculo: Bilbaoy la imaginación global. In: LASANSKY, D. M.; MCLAREN, B. (Org.). Arquitectura y turismo. Percepción, representación y lugar. Barcelona: Gustavo Gili, 2006. p. 261-273.

PAIVA, R. A. A metrópole híbrida: o papel do turismo no processo de urbanização da Região 
Metropolitana de Fortaleza. 2011. 305 f. Tese (Doutorado em Planejamento Urbano e Regional) - Faculdade de Arquitetura e Urbanismo, Universidade de São Paulo, São Paulo, 2011. . O turismo e as práticas socioespaciais. Revista Turismo \& Desenvolvimento (Online), v. 2, p. 1013-1024, 2012.

SÁNCHEZ, F. A reinvenção das cidades para um mercado mundial. Chapecó: Argos, 2003.

SANTAELLA, L. O Que é Semiótica. São Paulo: Brasiliense, 1983. (Coleção Primeiros Passos, v. 103).

SKLAIR, L. Iconic architecture and capitalist globalization. City, v. 10, n. 1. p. 21-47, 2006. . Iconic Architecture and the Culture-ideology of Consumerism Theory. Culture \& Society, n. 27, p. 135-159, sep. 2010.

VAINER, C. Pátria, empresa e mercadoria. Notas sobre a estratégia discursiva do Planejamento Estratégico Urbano. In: ARANTES, O.; MARICATO, E.; VAINER, C. A cidade do pensamento único. Desmanchando Consensos. Petrópolis: Vozes, 2002. p. 75-103.

VARGAS, H. C. Turismo Urbano: uma nova indústria motriz. Boletim de Turismo e Administração Hoteleira. São Paulo, v. 5, n. 2, p. 38-46, out. 1996.

VENTURI, R.; BROWN, D. S.; IZENOUR, S. Aprendendo com Las Vegas. São Paulo: Cosac Naify, 2003. (Coleção Face Norte, v. 3).

ZUKIN, S. Aprendendo com Disney World. Espaço \& Debates, São Paulo, v. 23, n. 43-44, p. 11-27, jan./dez. 2003.

A B S T R A C T : This paper analyzes theoretically and historically the relationship between tourism and urban and architectural icons, emphasizing their role in the contemporary scenario. It also focuses on the importance of these artefacts (buildings, great projects and urban interventions) in the context of urban competitiveness and productivity and thus in propagation of tourist image of places. It discusses critically how the logic of consumption reinforces the relationship between tourism, urban and architectural icons and tourist image, which are conditioned by social practices (economical, political and cultural-ideological) of globalization, that has greatly directed the urban planning, management, and intervention, as well as the spectacularization of architecture and promoting its symbolic power.

K E Y W O R D S : urban and architectural icons; tourism; architecture; urban intervention; placemarketing; tourist image. 